\title{
Isothermal and Two-Temperature Zone Selenization of Mo Layers
}

\author{
L. Kaupmees, ${ }^{1}$ M. Altosaar, ${ }^{1}$ O. Volobujeva, ${ }^{1}$ T. Raadik, ${ }^{1}$ M. Grossberg, ${ }^{1}$ \\ M. Danilson, ${ }^{1}$ E. Mellikov, ${ }^{1}$ and P. Barvinschi ${ }^{2}$ \\ ${ }^{1}$ Department of Materials Science, Tallinn University of Technology, Ehitajate tee 5, 19086 Tallinn, Estonia \\ ${ }^{2}$ Faculty of Physics, West University of Timisoara, B V. Boulovard Parvan 4, 300223 Timisoara, Romania
}

Correspondence should be addressed to L. Kaupmees, liina3112@staff.ttu.ee

Received 29 June 2011; Accepted 6 October 2011

Academic Editor: Pavel Lejcek

Copyright () 2012 L. Kaupmees et al. This is an open access article distributed under the Creative Commons Attribution License, which permits unrestricted use, distribution, and reproduction in any medium, provided the original work is properly cited.

\begin{abstract}
Glass/Mo, Mo foil, glass/Mo/In, and glass/Mo/Cu stacked layers were selenized in closed vacuum tubes by isothermal and/or twotemperature zone annealing in Se vapors. The selenization process was studied dependent on Se vapor pressure, temperature and time. Samples were selenized from 375 to $580^{\circ} \mathrm{C}$ for 30 and 60 minutes. The applied Se pressure was varied between 130 and $4.4 \cdot 10^{3} \mathrm{~Pa}$. The increase of $\mathrm{MoSe}_{2}$ film thickness was found to depend on the origin of Mo. MoSe $e_{2}$ thickness $d_{L}$ on Mo-foil was much higher than on sputtered Mo layers, and it depended linearly on time and as a power function $d_{L} \sim P_{\mathrm{Se}}^{1 / 2}$ on Se vapor pressure. The residual oxygen content in the formed $\mathrm{MoSe}_{2}$ layers was much lower in the two-zone selenization process. If Mo was covered with $\mathrm{Cu}$ or In before selenization, these were found to diffuse into formed $\mathrm{MoSe}_{2}$ layer. All the MoSe $\mathrm{M}_{2}$ layers showed p-type conductivity.
\end{abstract}

\section{Introduction}

Mo is widely used as a back contact material in thin film solar cells. In CuInSe $\mathrm{S}_{2}$-based solar cell production, Mo reacts with Se forming a thin layer of $\mathrm{MoSe}_{2}$. MoSe $\mathrm{M}_{2}$ has been extensively studied as a consequence of having both interesting physical properties (superconductivity, charge density waves, magnetism, etc.) and the ability to prepare many metastable derivates of these compounds via intercalation reactions [2]. $\mathrm{MoSe}_{2}$ has been reported as an efficient compound for photoelectrochemical conversion of solar energy [3]. $\mathrm{MoSe}_{2}$ in the form of a polycrystalline thin film has become an attractive semiconductor compound for electronics [4]. $\mathrm{MoSe}_{2}$ belongs to a class of compounds called layered transition metal dichalcogenides [2]. Hexagonal $\mathrm{MoSe}_{2}$ consists of planes of Mo covalently bonded to Se atoms, but these planes are weakly bonded to each other by Van der Waal forces. It has been suggested that the orientation of $\mathrm{MoSe}_{2}$ planes with respect to the Mo substrate plays an important role in adhesion and electrical properties. Good adhesion between Mo and $\mathrm{MoSe}_{2}$ is observed when $\mathrm{MoSe}_{2}$ layers are oriented perpendicular to the Mo substrate (it means $\mathrm{MoSe}_{2}$ with $c$-axis parallel to Mo surface) since a strong covalent bond can form at the interface between Se and the underlying Mo. So, it is important for the practical use of Mo substrates in solar cell production to determine the growth orientation of $\mathrm{MoSe}_{2}$ with respect to the surface and the rate of selenization. Bernède et al. found that it is necessary to anneal an Mo layer at temperatures higher than $377^{\circ} \mathrm{C}$ to obtain reproducibly $\mathrm{MoSe}_{2}$ layers without any other phase [5]. There is till limited information on the mechanism of selenization of Mo and no quantitative model describing $\mathrm{MoSe}_{2}$ formation. Up to now, only Krishnan et al. have discussed on the reaction pathways during selenization of Mo [6].

In this paper, we present the results of selenization of Mo and of $\mathrm{MoSe}_{2}$ formation in isothermal and two-temperaturezone selenization processes.

\section{Experimental Details}

2.1. Sample Preparation. Different Mo substrates were used, like Mo-foil, glass/Mo, glass/Mo/In, and glass/Mo/Cu. Molybdenum substrates, cleaned by dry etching in Ar plasma for 5 minutes, together with Se pellets, were sealed into quartz vacuum ampoules after pumping down to $13 \cdot 10^{-3} \mathrm{~Pa}$. The quartz ampoules $(1 \mathrm{~cm}$ in diameter and $7 \mathrm{~cm}$ (isothermal 


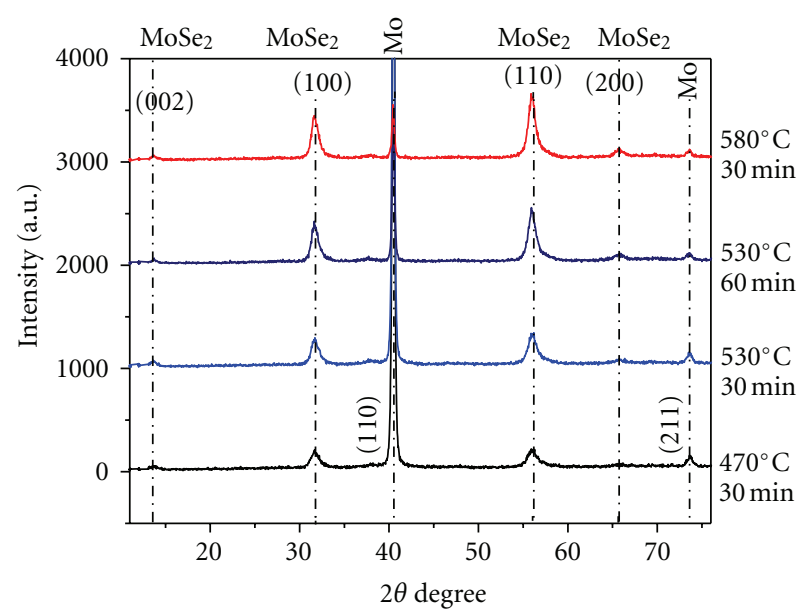

FIgURE 1: XRD patterns of $\mathrm{Mo} / \mathrm{MoSe}_{2}$ samples annealed in the isothermal conditions at 470,530 , and $580^{\circ} \mathrm{C}$ for 30 and 60 minutes. Two upper patterns belong to samples selenized under Ar overpressure.

selenization) or $35 \mathrm{~cm}$ (2-zone selenization) in length) were etched with a mixture of concentrated $\mathrm{HF}+\mathrm{HNO}_{3}(1: 1)$, rinsed with DI water, and heated in the flame of $\mathrm{C}_{3} \mathrm{H}_{8}+\mathrm{O}_{2}$ gas prior using.

The filled ampoules were inserted into a preheated horizontal tube furnace and heated for different periods (up to 1 hour). Mo substrates were selenized by two different methods: (1) isothermal (one-zone) selenization: the Mo samples $\left(0.75 \times 2.5 \mathrm{~cm}^{2}\right)$ and elemental selenium were heated in the same temperature zone, where the pressure of Se vapor is determined by the used annealing temperature $(375,470$, 530 , and $580^{\circ} \mathrm{C}$ ); (2) two-zone selenization: samples were annealed in a two-temperature-zone quartz tubular vacuum reactor where temperatures of the Se source and the reaction zone, were controlled and regulated independently. Mo substrates were heated in the higher temperature zone for at 470 , 530 , and $580^{\circ} \mathrm{C}$, while the inexhaustible selenium source (Se pellets) was heated in the lower temperature zone to produce controlled reactive Se vapor atmosphere between 130 and $4.4 \cdot 10^{3} \mathrm{~Pa}$. After annealing, in both cases, the ampoules were taken out of the furnace and cooled down on a ceramic plate at room temperature.

2.2. Characterization Techniques. Produced films have been studied by X-ray diffraction (XRD) method on a Bruker D8 Advance diffractometer, by energy dispersive X-ray spectroscopy (EDX) method using a Röntec EDX XFlash 3001 detector and by RT Raman spectroscopy using a Horiba's LabRam high resolution spectrometer equipped with a multichannel detection system in the backscattering configuration. The conductivity type of selenized samples was determined by the hot probe method. The surface morphology and thickness of selenized layers were studied and determined by a high resolution scanning electron microscope Zeiss Ultra 55 SEM. X-ray photoelectron spectroscopy (XPS), AXIS Ultra ${ }^{\text {DLD }}$, was used to characterize the surface chemical composition of formed layers.

\section{Results and Discussion}

\subsection{Characterization of Isothermally Selenized Glass/Mo Films}

3.1.1. Morphological and Structural Study of $\mathrm{MoSe}_{2}$ by SEM and XRD. $1 \mathrm{~mm}$ thick glass substrates covered with $1 \mu \mathrm{m}$ thick Mo layer (marked as glass $/ \mathrm{Mo}^{2}$ ), dc. sputtered in ZSW (Zentrum für Sonnenenergie und Wasserstoff-Forschung, Stuttgart) were used. XRD and EDX measurements suggest that the Mo-Se compound formed by selenization can be identified as $\mathrm{MoSe}_{2}$. The composition of Mo-Se films on metallic Mo substrates analysed by EDX method was found to be Mo: $\mathrm{Se}=1: 2$. XRD patterns of selenized glass/Mo samples (see Figures 1 and 4(c)) show peaks corresponding to the hexagonal $\mathrm{MoSe}_{2}$ phase [JCPDS cards 29-0914; 77-1715 and 87-2419]. All the synthesized $\mathrm{MoSe}_{2}$ layers had p-type conductivity.

Analyzing samples that were selenized for 30 minutes at different temperatures under isothermal conditions, the following features can be drawn.

(1) $\mathrm{MoSe}_{2}$ grown at $375^{\circ} \mathrm{C}$ was nonorientated; the surface was not smooth nor dense and porous. The total thickness of the $\mathrm{Mo} / \mathrm{MoSe}_{2}$ layers was about $1.3 \mu \mathrm{m}$, wherefrom the $\mathrm{MoSe}_{2}$ layer thickness was determined to be approximately $250 \mathrm{~nm}$.

(2) Annealing at $470^{\circ} \mathrm{C}$ resulted in $\mathrm{MoSe}_{2}$, composed of two layers, the top layer was similar to the previously described $375^{\circ} \mathrm{C}$ layer and the next layer under the top layer (following the initial layered structure of as deposited Mo) was orientated with the $c$-axis parallel to the Mo surface. The total thickness of the formed $\mathrm{MoSe}_{2}$ was around $1.5 \mu \mathrm{m}$, with thicknesses of the two layers described above being 700 and $800 \mathrm{~nm}$, respectively. According to SEM analysis, thickness of the upper nonorientated layer of $\mathrm{MoSe}_{2}$ diminished with increasing the selenization temperature.

(3) The selenization at $530^{\circ} \mathrm{C}$ was found to be a breaking point from where (at higher temperatures) mainly $\mathrm{MoSe}_{2}$ with $c$-axis parallel to Mo surface grows. Although 30 minutes selenization resulted in a mixture of $\mathrm{MoSe}_{2}$ with $c$-axis parallel and perpendicular to the Mo layer. The surface layer was quite thin, about $330 \mathrm{~nm}$, which is expected to disappear with prolonged process.

With increasing selenization temperature from 470 to $530^{\circ} \mathrm{C}$, the orientation of the $\mathrm{MoSe}_{2}$ layers changes from perpendicular to an almost parallel alignment with respect to the Mo substrate plane, as it was also found in [5]. In [8], the authors connected the change in $\mathrm{MoS}_{2}$ orientation with the formation of an intermediate solid solution $\mathrm{Na}_{2} \mathrm{~S}_{x}-\mathrm{MoS}_{2}(x=$ $1-6 \neq 5)$ at temperatures higher than $550^{\circ} \mathrm{C}$. Similar behavior can be proposed in the case of $\mathrm{MoSe}_{2}$ because of the close values of electronic affinities of Se and S (2.4 and 2.5 , resp.). The only sodium source in our case can be the used glass substrates. Na out-diffusion from SLG substrate plays an important role also in the fabrication of CIGSbased solar cells enabling the growth of the crystals of the 

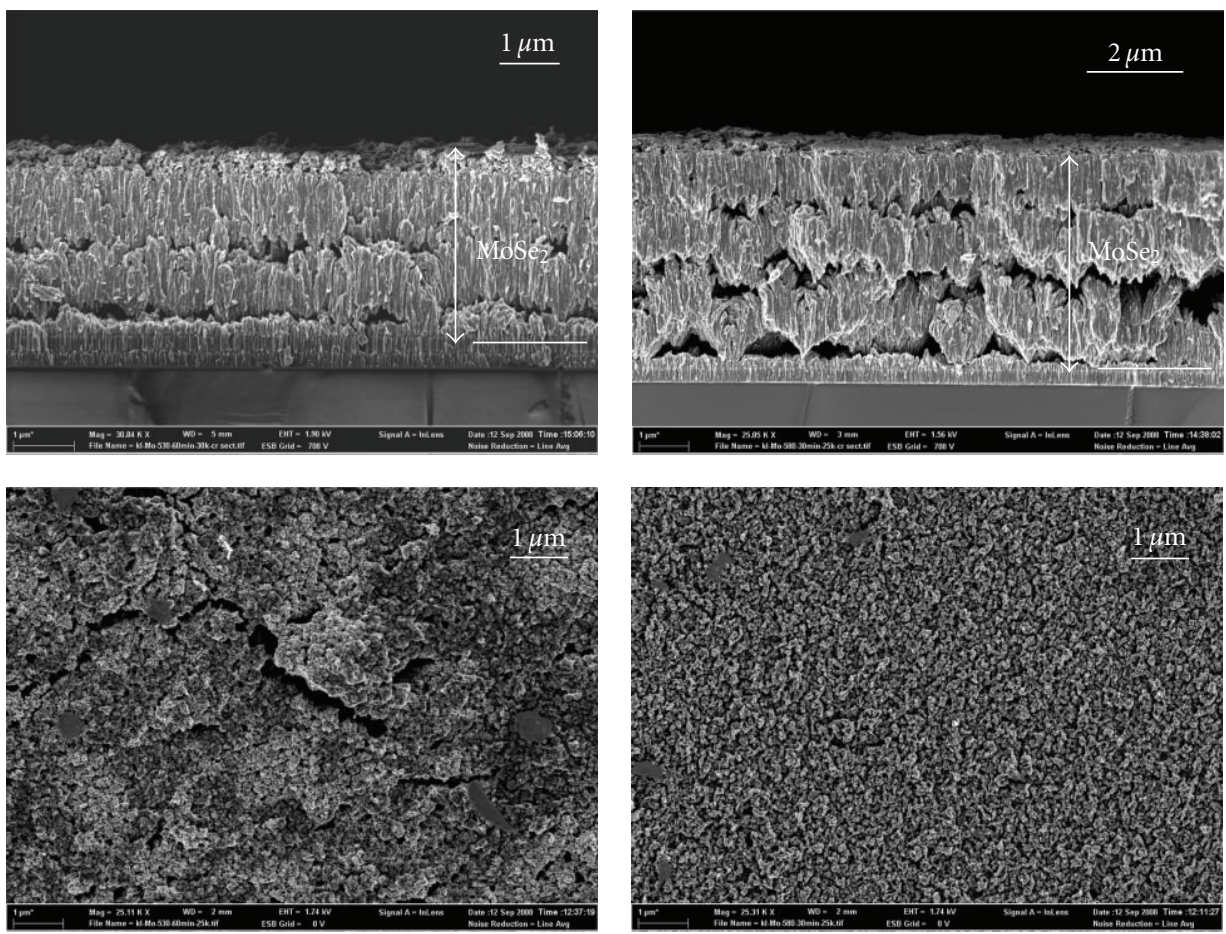

(a)

(b)

Figure 2: SEM cross-sectional and surface images of $\mathrm{Mo} / \mathrm{MoSe}_{2}$ samples annealed under Ar overpressure in the isothermal conditions at $530^{\circ} \mathrm{C}$ for 60 minutes (a) and at $580^{\circ} \mathrm{C}$ for 30 minutes (b).

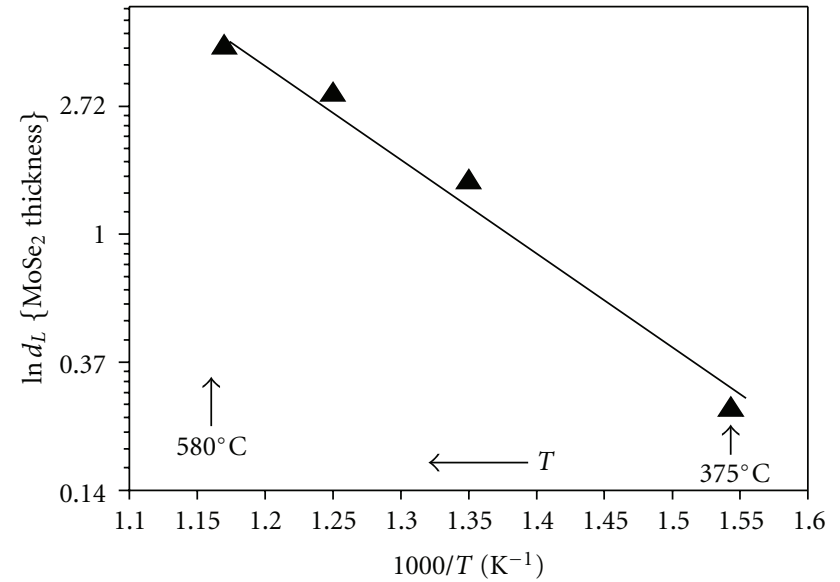

FIgURe 3: Thickness of $\mathrm{MoSe}_{2}$ on glass/Mo dependent on reciprocal selenization temperature. Straight line remarks the linear fitting of test points.

absorber material [9], as it is known that sputtered Mo layers contain molybdenum oxides in Mo grain boundaries $[8,10]$ that create efficient channels for $\mathrm{Na}$ diffusion [10]. From $\mathrm{Na}-\mathrm{Se}$ phase diagram [11], it is seen that at around $495^{\circ} \mathrm{C}$ there occurs peritectic transformation of $\mathrm{Na}_{2} \mathrm{Se}_{2}$ to $\mathrm{Na}_{2} \mathrm{Se}$ and liquid Se forms. The latter can act as liquid flux for recrystallisation of both the CIGS absorber material and $\mathrm{MoSe}_{2}$ crystals. At low Se partial pressure, the formation of $\mathrm{Na}_{2} \mathrm{Se}_{x}$ $(x=1)$ dominates and no Se is available. This was used to explain the lowered selenization of Mo in the presence of $\mathrm{Na}$ at low Se partial pressure [12]. At high Se partial pressure, the formation of $\mathrm{Na}_{2} \mathrm{Se}_{x}(x>1)$ dominates and Se is available for Mo selenization at higher than $495^{\circ} \mathrm{C}$. The reason for the evolution of the described upper layer of $\mathrm{MoSe}_{2}$ in the isothermal selenization process, where the Se source and the Mo sample are placed into the close vicinity of each other, could be the rapid selenium flow from the Se source to the Mo sample surface in the initial period of the process when occurs the temperature difference between the colder sample and the hotter ampoule wall. Jäger-Waldau et al. studied $\mathrm{MoSe}_{2}$ film composition and morphology, and they also found that the $\mathrm{MoSe}_{2}$ orientation depended on selenium partial pressure [13].

XRD patterns (Figure 1) of the Mo-Se films prepared in the isothermal selenization conditions at 470,530 , and $580^{\circ} \mathrm{C}$ show peaks related to $\mathrm{MoSe}_{2}$ [JCPDS cards 29-0914; 77-1715 and 87-2419] and indicate to the preferential growth of hexagonal $\mathrm{MoSe}_{2}$ in the (100) and (110) direction. Similar results were found in [5]. The preferential orientation of $\mathrm{MoSe}_{2}$ with respect to the Mo substrate facilitates the diffusion of Se through the already formed $\mathrm{MoSe}_{2}$, thus leading to the growth of thicker $\mathrm{MoSe}_{2}$ layers. The preferred orientation in (100) and (110) direction, that is, the average orientation of the $c$-axis of the $\mathrm{MoSe}_{2}$ layer parallel to the Mo surface, becomes more pronounced for $\mathrm{MoSe}_{2}$ layers grown at 530 and $580^{\circ} \mathrm{C}$ for 60 and 30 minutes, respectively. XRD patterns indicate also to unreacted Mo in each sample with preferred orientation in the (110) direction [JCPDS card 42-1120]. 

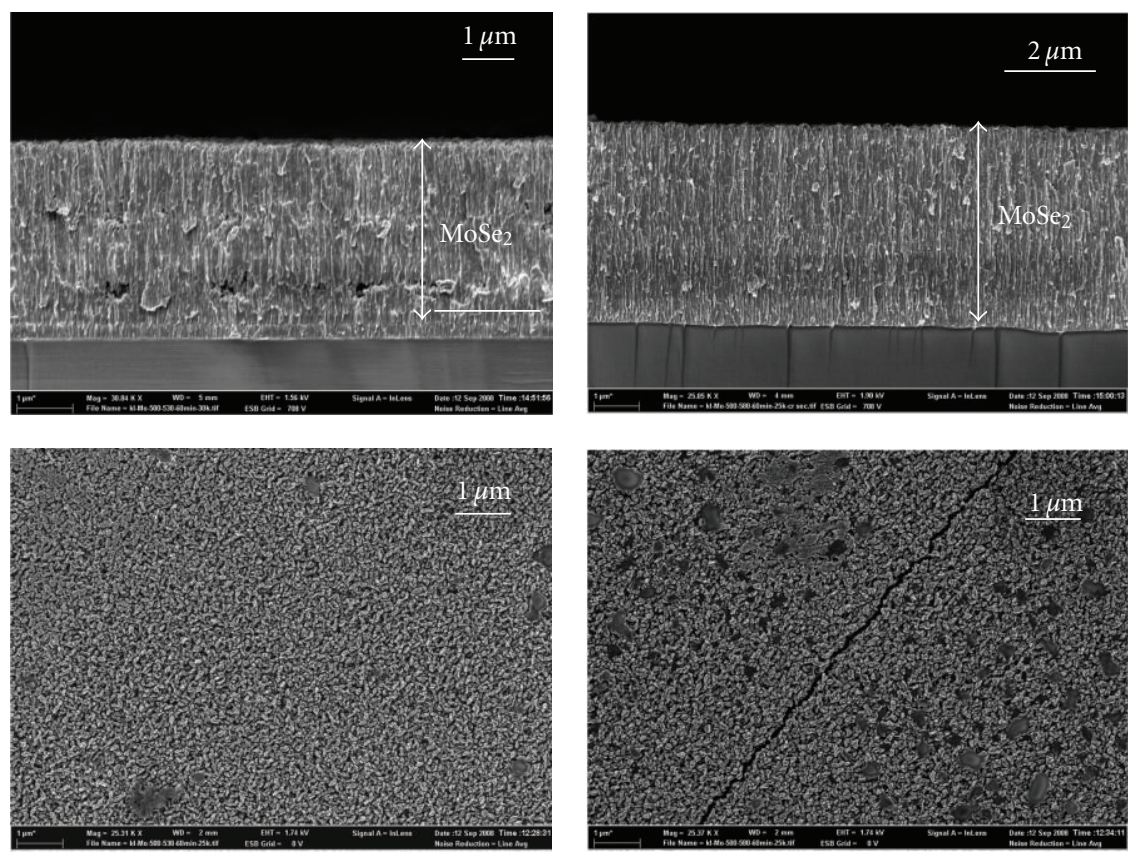

(a)

(b)

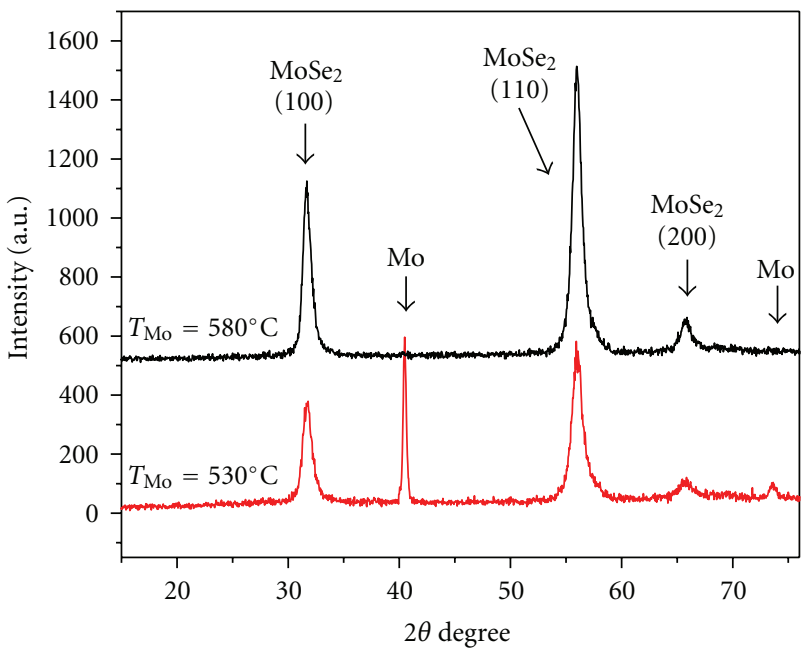

(c)

Figure 4: (a, b) SEM cross-sectional and surface images of glass $/ \mathrm{Mo}^{2}$ samples selenized for $1 \mathrm{~h}$ at $530^{\circ} \mathrm{C} \mathrm{(a)}$ and $580^{\circ} \mathrm{C}(\mathrm{b})$ in two-zone ampoules under selenium vapor pressure of $4.4 \cdot 10^{3} \mathrm{~Pa}\left(T_{\mathrm{Se}}=500^{\circ} \mathrm{C}\right)$; (c) XRD patterns of selenized samples.

Using argon environment during the selenization, we can balance the processes taking place, to hold back the reaction and condensation of selenium on the surfaces of the samples.

Selenization in the isothermal process arrangement at higher temperatures $\left(530\right.$ and $580^{\circ} \mathrm{C}$ ) causes intense selenization of Mo corresponding to a quite high selenium pressures determined by the used temperatures. SEM cross-sectional images of $\mathrm{Mo} / \mathrm{MoSe}_{2}$ samples annealed in the isothermal conditions at $530^{\circ} \mathrm{C}$ for 60 minutes and at $580^{\circ} \mathrm{C}$ for 30 minutes under Ar overpressure are presented in Figure 2 and indicate that all the layers are full of cracks.

3.1.2. Growth Rate of $\mathrm{MoSe}_{2}$ Layer in Isothermal Selenization Process. The thickness of $\mathrm{MoSe}_{2}$ on glass/Mo samples follows the Arrhenius equation; the thickness (in native logarithmic scale) of the formed $\mathrm{MoSe}_{2}$ layer increases linearly with the reciprocal selenization temperature (see Figure 3 ). From the Arrhenius plot, the activation energy of the layer growth process was found to be $-E_{a}=0.7 \pm 0.1 \mathrm{eV}$ that is close to the activation energy found in [6].

3.2. Two-Zone Selenization of Mo Substrates. Selenization of glass $/ \mathrm{Mo}^{2}$ substrates for 60 minutes at 530 and $580^{\circ} \mathrm{C}$ under selenium vapor pressure of $4.4 \cdot 10^{3} \mathrm{~Pa}\left(T_{\mathrm{Se}}=500^{\circ} \mathrm{C}\right)$ resulted in dense and thick layers of $\mathrm{MoSe}_{2}$ (see Figures 4(a) and 4(b)). The comparision of the corresponding XRD patterns (see Figure 4(c)) show that $\mathrm{MoSe}_{2}$ layers selenized at $580^{\circ} \mathrm{C}$ have better crystallinity compared with $530^{\circ} \mathrm{C}$ (peaks are narrower and higher in the diffractogram), but the Mo layer is 


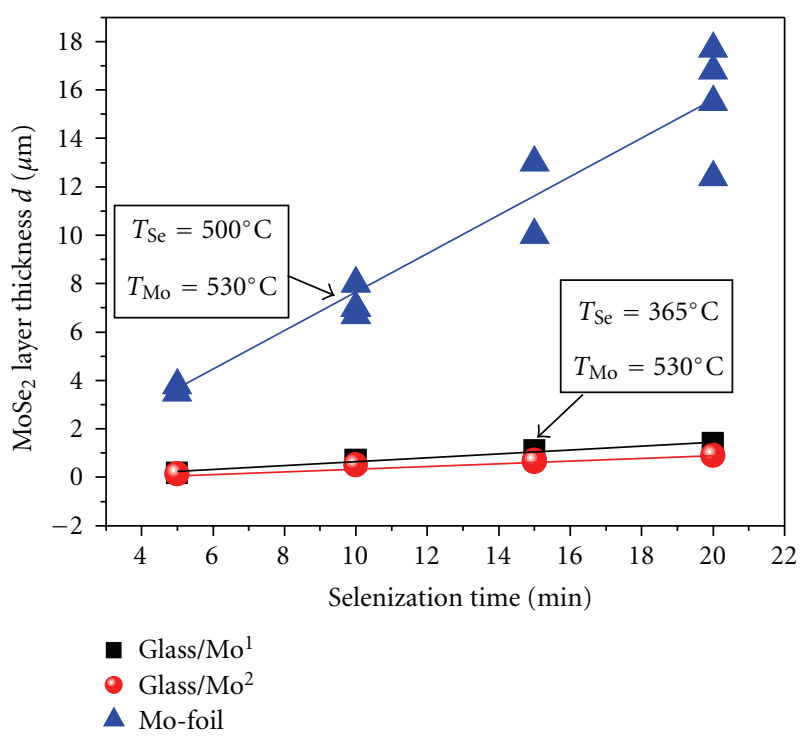

(a)

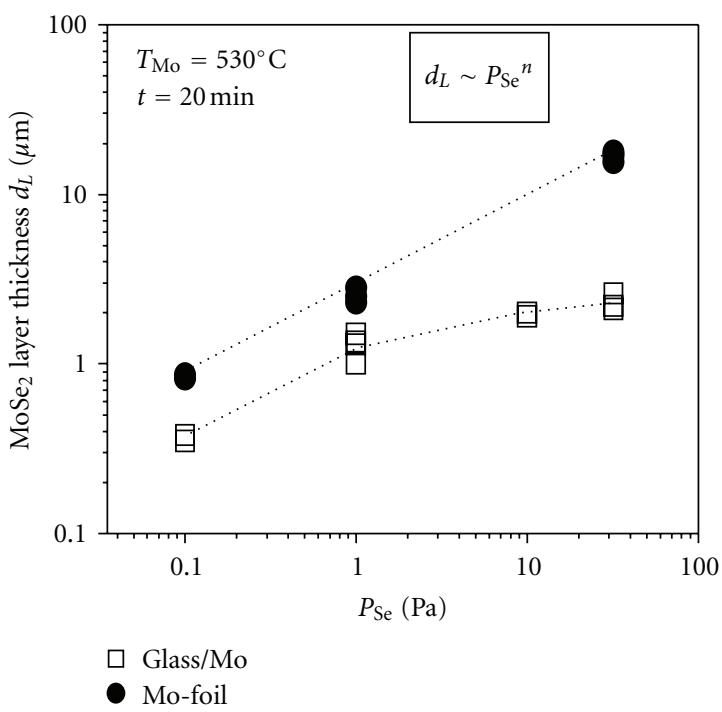

(b)

FIGURE 5: Thickness of $\mathrm{MoSe}_{2}$ layer dependent on selenization time (a) and on Se vapor pressure (b).

thoroughly selenized at $580^{\circ} \mathrm{C}$; Mo peak had disappeared in XRD pattern.

3.2.1. Growth Rate of $\mathrm{MoSe}_{2}$. Two types of sputtered glass/ Mo substrates-(1) rf sputtered $\left(\mathrm{Mo}^{1}\right)$ and (2) dc sputtered $\left(\mathrm{Mo}^{2}\right)$ and $\mathrm{Mo}$-foil were used in two-zone selenization to find out the dependences of Mo-Se layer thickness on selenization time and on Se vapor pressure. Graphs are presented in Figures 5(a) and 5(b); more detailed information is given in [14]. Figure 5(a) shows that the thickness of $\mathrm{MoSe}_{2}$ layer on Mo selenized at $530^{\circ} \mathrm{C}$ in constant Se vapor pressure increases linearly with the increase of selenization duration. The thickness of the $\mathrm{MoSe}_{2}$ layer on Mo-foil increases with the rate of about $0.7 \mu \mathrm{m}$ per minute at $530^{\circ} \mathrm{C}$ and $P_{\mathrm{Se}}=$ $4.4 \cdot 10^{3} \mathrm{~Pa}\left(T_{\mathrm{Se}}=500^{\circ} \mathrm{C}\right)$. The thickness of $\mathrm{MoSe}_{2}$ film on

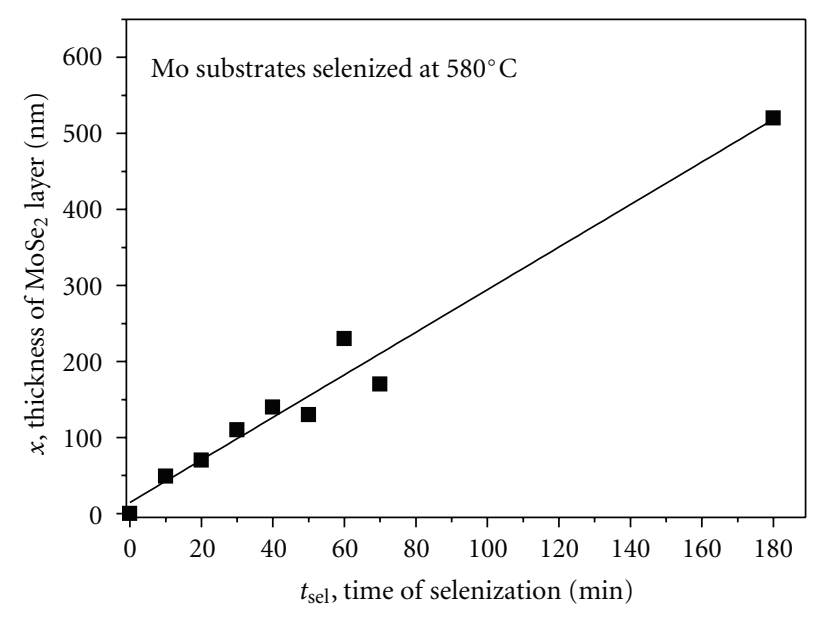

Figure 6: The thickness $x$ of $\mathrm{MoSe}_{2}$ layer versus the selenization duration $t_{\text {sel }}, T_{\text {Substrate }}=580^{\circ} \mathrm{C}$; the dashed curve gives the $x\left(t_{\text {sel }}\right)$ square root dependence with $D=5 \times 10^{-14} \mathrm{~cm}^{2} / \mathrm{s}$. [1]. The solid line marks the linear fit.

sputtered glass/Mo samples depends on the origin of initial Mo layer and technology of its production. For example, the thickness of $\mathrm{MoSe}_{2}$ on the glass/ $\mathrm{Mo}^{1}$ samples after annealing for 20 minutes at $530^{\circ} \mathrm{C}$ under the selenium pressure of $130 \mathrm{~Pa}\left(T_{\mathrm{Se}}=365^{\circ} \mathrm{C}\right)$ was about 1.5 times bigger than the one on the glass $/ \mathrm{Mo}^{2}$ substrates $(1.3$ and $0.9 \mu \mathrm{m}$, resp.) resulting in growth rates of about $65 \mathrm{~nm} / \mathrm{min}$. and $45 \mathrm{~nm} / \mathrm{min}$., respectively, (Figure 5(a) and [14]). The growth rate of $\mathrm{MoSe}_{2}$ layer in our experiments is much higher than the growth rate found in [1] $(3 \mathrm{~nm} / \mathrm{min}$.) for dc sputtered Mo on Si substrates, where the selenization was also performed in the twozone arrangement at $577^{\circ} \mathrm{C}$, but in a carrier gas stream where the process rate was regulated and suppressed by the inflow of Se. The authors [1] explained the growth of $\mathrm{MoSe}_{2}$ layer thickness as a process limited by the diffusion of Se atoms through the as-grown $\mathrm{MoSe}_{2}$ layer, and they fitted the experimental data and estimated the value of diffusion coefficient of Se in $\mathrm{MoSe}_{2}$ from the dependence $D=x^{2} / 2 t$, where $x$ means the thickness of $\mathrm{MoSe}_{2}$ layer (in the present study $d_{L}$ ) and $t$ is selenization duration. From the above-given equation, $x$ is equal to $x=\sqrt{ } 2 D t$. It means that thickness has to increase with time in square root function dependence (see the dashed curve in Figure 6). The fitting used in [1] does not coincide even well with all the experimental data of the work. Linear dependence fits match much better for all the experimental data of [1] (straight line in Figure 6). It means that our results and the results of [1] are pointing out the similar dependence: the linear increase of $\mathrm{MoSe}_{2}$ layer thickness with duration of selenization.

The dependence of the $\mathrm{MoSe}_{2}$ layer thickness on selenium vapor pressure both for Mo-foil and for sputtered $\mathrm{Mo} /$ glass samples is presented in Figure 5(b). The growth of $\mathrm{MoSe}_{2}$ layer thickness $d_{L}$ on Mo-foil depending on Se vapor pressure could be described as a power function: $d_{L} \sim P_{\mathrm{Se}}^{1 / 2}$. If we to consider that the vapor phase of selenium at temperatures used in the present work consists of molecules given in Table 1, from where it can be seen that $\mathrm{Se}_{2}$ and $\mathrm{Se}_{5}$ molecules 

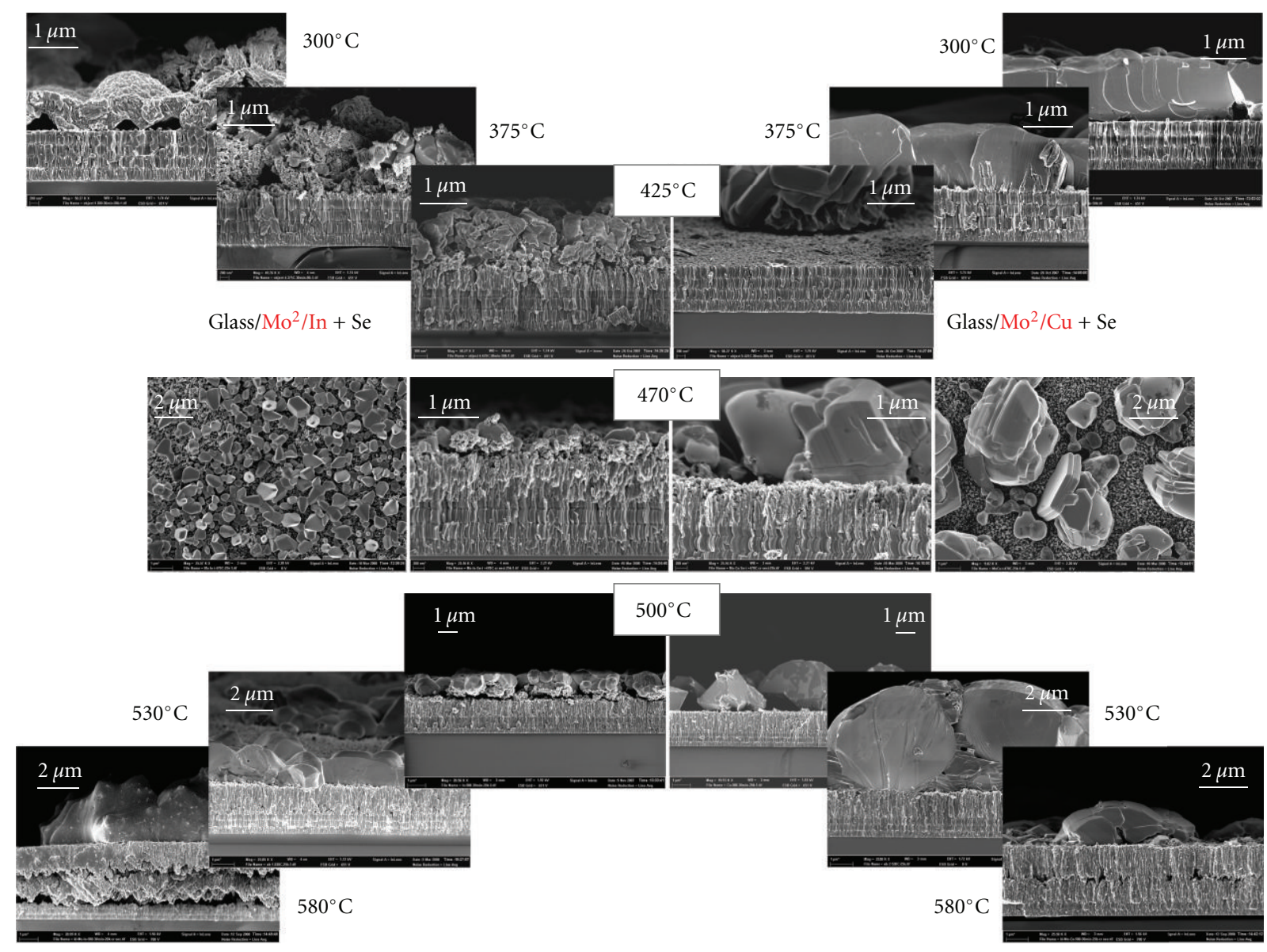

FIGURE 7: SEM micrographs of selenized glass/Mo/In and glass/Mo/Cu substrates, the structural evolution of layers selenized at different temperatures.

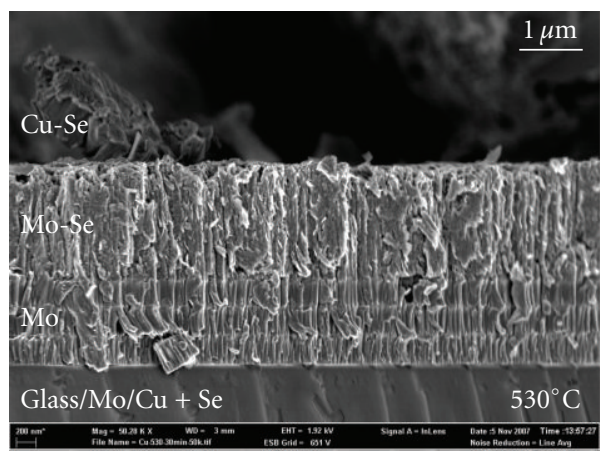

(a)

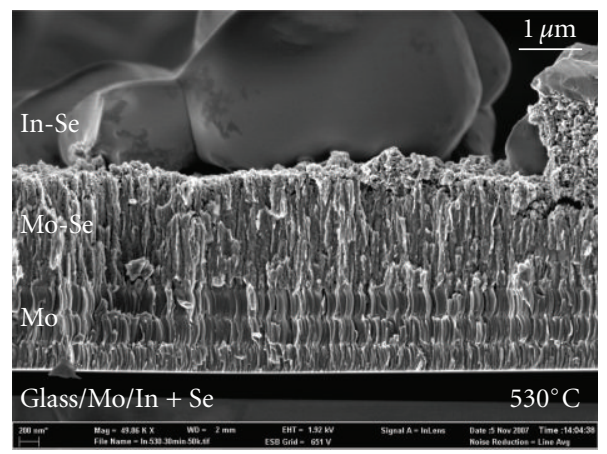

(b)

FIGURE 8: SEM micrographs of $\mathrm{Mo} / \mathrm{Cu}$ (a) and $\mathrm{Mo} / \mathrm{In}(\mathrm{b})$ layers selenized at $530^{\circ} \mathrm{C}$.

TABle 1: Partial pressure (atm.) of different Se molecules in vapor phase of Se [7].

\begin{tabular}{lcccccccc}
\hline $\mathrm{T}, \mathrm{K}$ & $\mathrm{T},{ }^{\circ} \mathrm{C}$ & $\sum$ Pse, atm. & $\mathrm{Se}_{2}$ & $\mathrm{Se}_{3}$ & $\mathrm{Se}_{5}$ & $\mathrm{Se}_{6}$ & $\mathrm{Se}_{7}$ \\
\hline 650 & 377 & $2.46 \times 10^{-3}$ & $5.54 \times 10^{-4}$ & $1.32 \times 10^{-5}$ & $1.32 \times 10^{-3}$ & $3.89 \times 10^{-4}$ & $1.55 \times 10^{-4}$ & $2.75 \times 10^{-5}$ \\
\multicolumn{2}{l}{ Partial pressure (\%) } & 100 & 22.5 & 0.54 & 53.66 & 15.8 & 6.3 \\
800 & 527 & $9.2 \times 10^{-2}$ & $2.35 \times 10^{-2}$ & $1.26 \times 10^{-4}$ & $5.76 \times 10^{-2}$ & $6.92 \times 10^{-3}$ & $3.23 \times 10^{-3}$ & $5.88 \times 10^{-4}$ \\
\multicolumn{2}{l}{ Partial pressure (\%) } & 100 & 25.54 & 0.14 & 62.61 & 7.52 & 3.51 & 0.64 \\
\hline
\end{tabular}



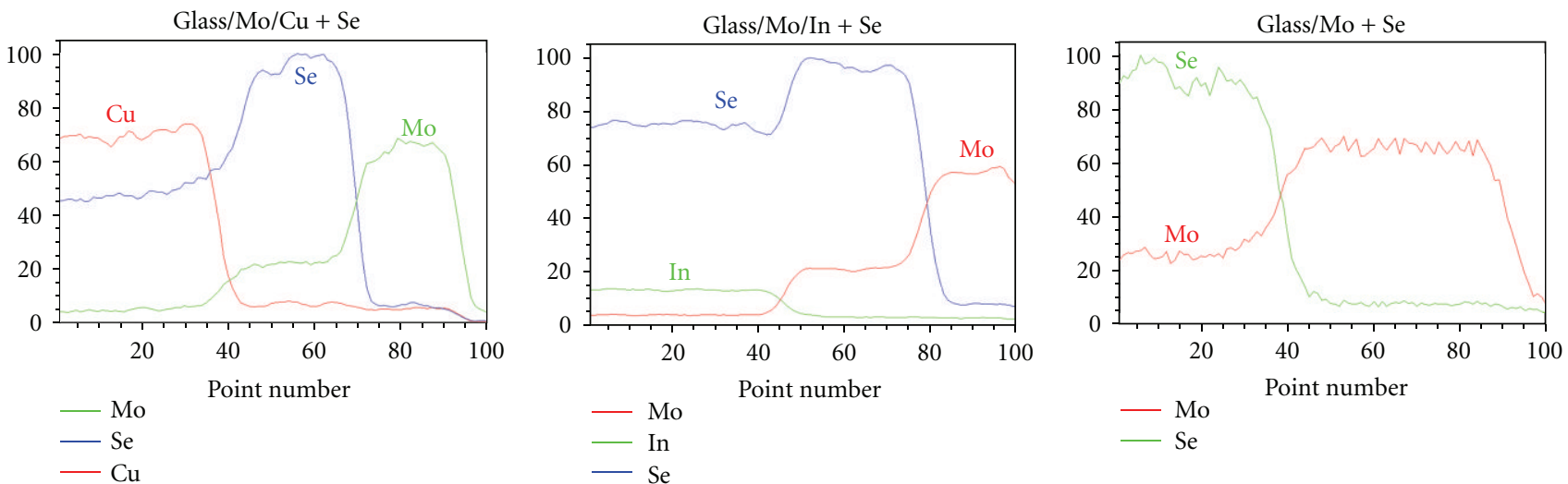

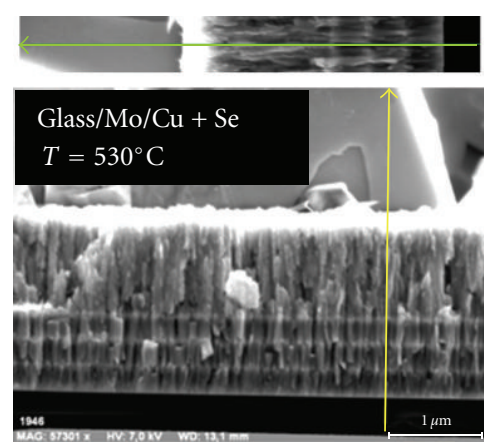

(a)
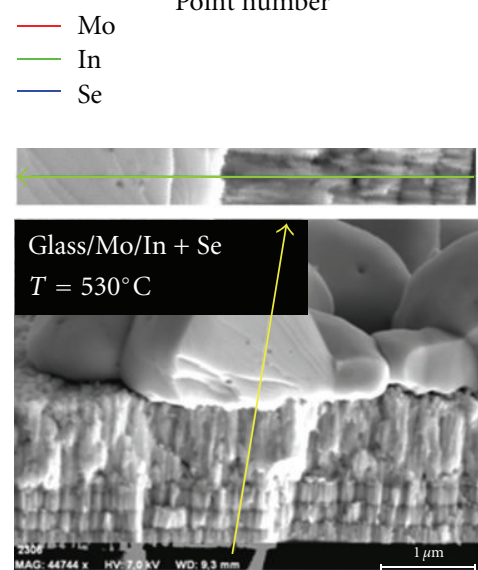

(b)
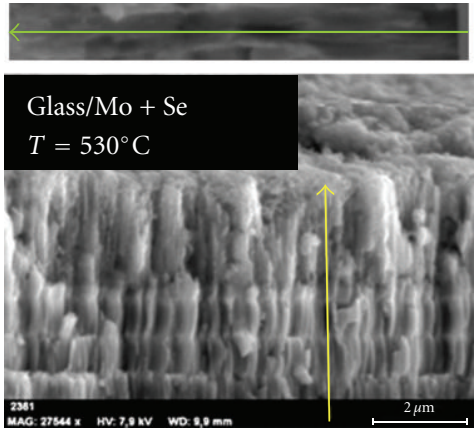

(c)

FIGURE 9: EDS line scanning profile of the cross section of glass/Mo, glass/Mo/In, and glass/Mo/Cu layers selenized at $530^{\circ} \mathrm{C}$ for 30 minutes.

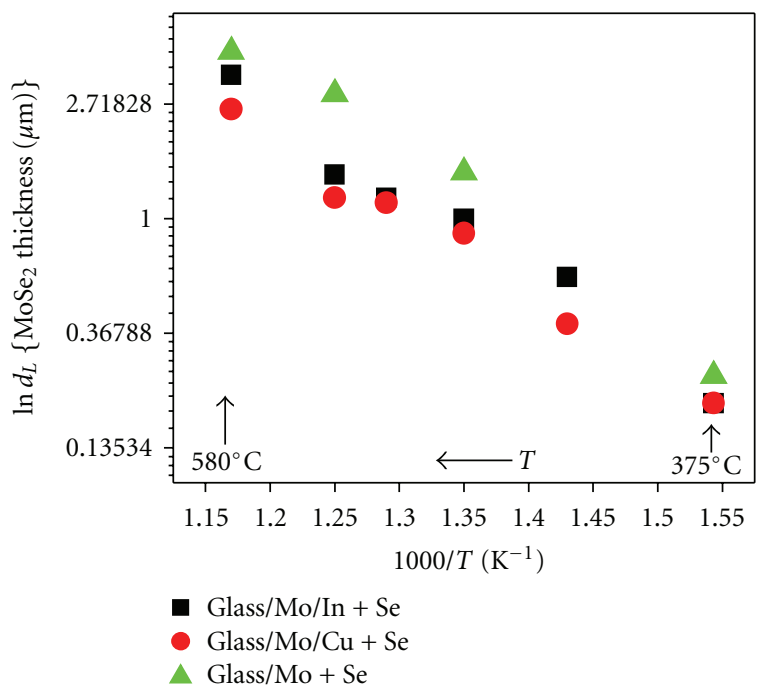

Figure 10: Thickness of $\mathrm{MoSe}_{2}$ on glass/Mo, glass/Mo/In, and glass/ $\mathrm{Mo} / \mathrm{Cu}$ dependent on reciprocal selenization temperature.

(weight average around 4 atoms) prevail in the used temperature range, the formation process of $\mathrm{MoSe}_{2}$ at constant temperature can be written as follows:

$$
\mathrm{Mo}+\frac{1}{2} \mathrm{Se}_{4} \text { (weight average) } \longrightarrow \mathrm{MoSe}_{2} \text {. }
$$

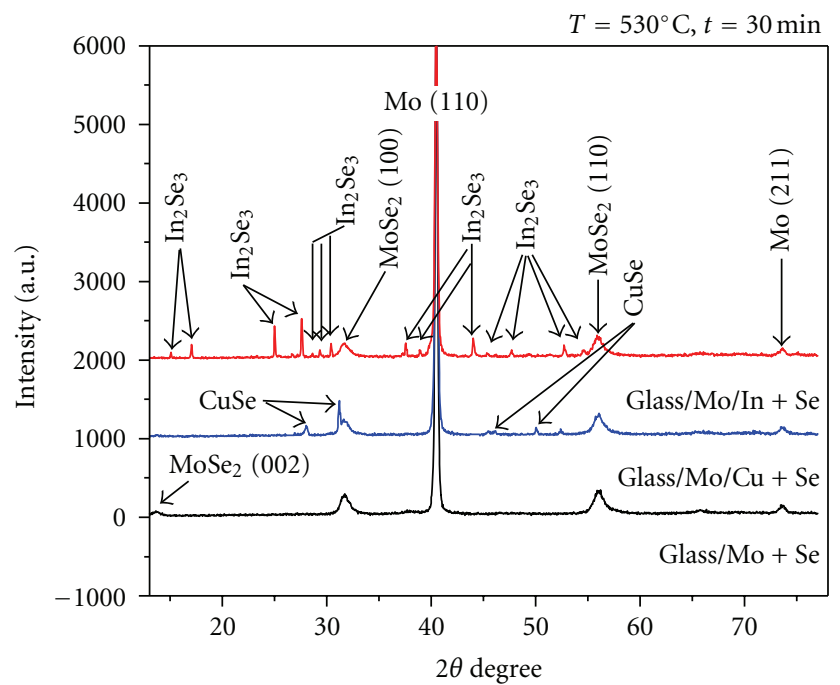

Figure 11: XRD patterns of glass/Mo, glass/Mo/In, and glass/Mo/ $\mathrm{Cu}$ layers selenized isothermally at $530^{\circ} \mathrm{C}$ for 30 minutes.

On the basis of the reaction (1), the thickness of $\mathrm{MoSe}_{2}$ layer $d_{L}$ dependent on Se vapor pressure can be described as

$$
d_{L} \sim k P_{\mathrm{Se}}^{1 / 2}
$$

where $k$ is the velocity constant of reaction (1). This result could be explained by the straggling Mo grains in Mo-foil 


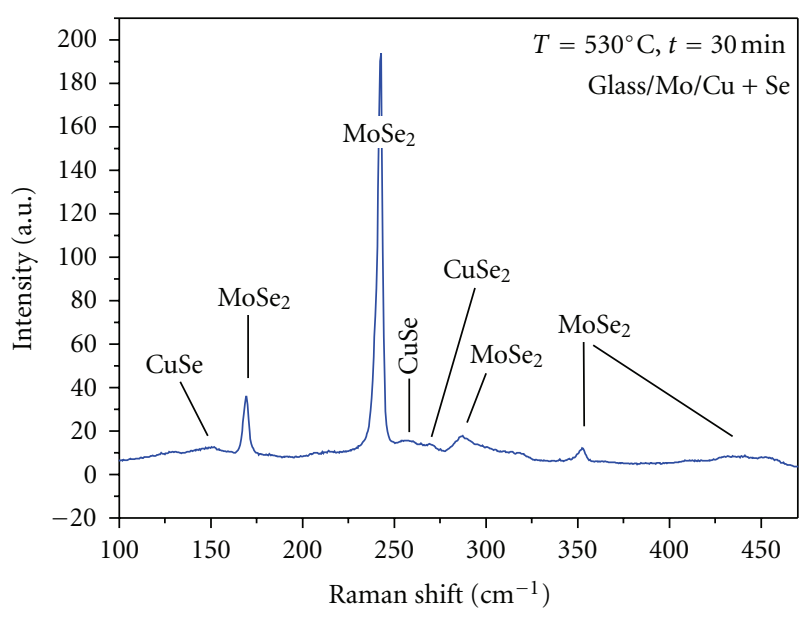

(a)

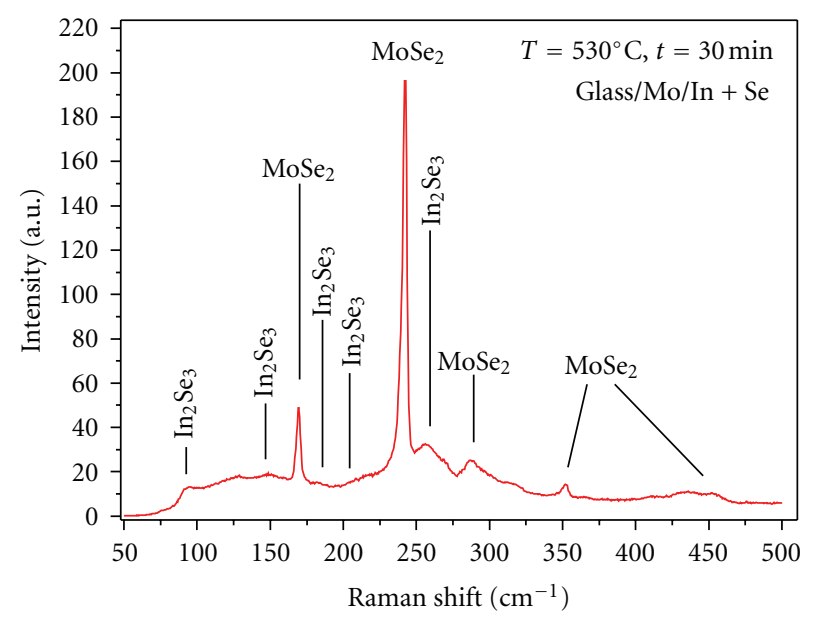

(b)

Figure 12: Raman spectra of (a) glass/Mo/Cu layers and of (b) glass/Mo/In layers selenized at $530^{\circ} \mathrm{C}$ for 30 minutes.

that enable fast diffusion of Se atoms through the grown $\mathrm{MoSe}_{2}$ layer. This dependence confirms that selenization of Mo foil is limited by selenium availability on the interface and not by the diffusion of Se through $\mathrm{MoSe}_{2}$. The regularities of selenization of dense sputtered Mo layers differ from the regularities of selenization of Mo-foil. The similar, $d_{L} \sim P_{\mathrm{Se}}^{1 / 2}$, behavior is visible only in the low Se vapor pressure region (see Figure 5(b)). The growth of $\mathrm{MoSe}_{2}$ layer proceeds due to the diffusion of selenium atoms or molecules through dense-layered structure of $\mathrm{MoSe}_{2}$ followed by their subsequent interaction with molybdenum atoms at the Mo$\mathrm{MoSe}_{2}$ interface. As $\Delta \mathrm{G}$ of the reaction $\mathrm{Mo}+\mathrm{Se}_{2} \rightarrow \mathrm{MoSe}_{2}$ is negative at $530^{\circ} \mathrm{C}: \Delta \mathrm{G}=-145 \mathrm{~kJ}$, we can conclude that the difference in the density of Mo in substrates of various origin could be the reason for different packing density of columnar structure of $\mathrm{MoSe}_{2}$ as well, and this is the reason of different growth rates under the same processing conditions.

3.3. Comparison of Isothermal and Two-Zone Arrangements of the Selenization Process of Mo. In the isothermal arrangement, the selenium source and the Mo sample are situated in close vicinity to each other in the same temperature zone. Rapid formation of a relatively high vapor pressure of Se in the vicinity of the Mo sample (determined by the heat treatment temperature) allows faster start of the $\mathrm{MoSe}_{2}$ formation reaction in comparison with two-temperature zone arrangement, where the Se source is at a distance of about $30 \mathrm{~cm}$ from the reaction zone. In the isothermal arrangement the extent of selenization of Mo could be tailored by the amount of Se in the reaction ampoule. For example, heating for one hour at $530^{\circ} \mathrm{C}$ resulted in thoroughly consumed Se and partly selenized Mo layers with the final thickness of $\mathrm{Mo} / \mathrm{MoSe}_{2}$ layer of about $3 \mu \mathrm{m}$ (possible maximum thickness being $4.4 \mu \mathrm{m}$ ). XRD analysis confirmed the existence of both unreacted Mo and $\mathrm{MoSe}_{2}$ phases. SEM investigations of surface morphology did not show any cracks in layers. However, after 30-minute selenization at $580^{\circ} \mathrm{C}$, nearly the same thickness of $\mathrm{MoSe}_{2}$ layer was gained with the same amount of Se. This means that the amount of Se was limiting the process of selenization in the isothermal arrangement. We can conclude that the selenization process in isothermal arrangement can be controlled by the annealing time or the process can be limited by the added amount of elemental Se.

Experiments showed that the optimum selenization temperature of Mo layers is $530^{\circ} \mathrm{C}$. At higher temperatures, the tension between the layers is remarkable and as a result thermal stresses resulted in cracks. If the layer is growing too fast or the Mo layer is thoroughly selenized to $\mathrm{MoSe}_{2}$, there could occur adhesion problems, peeling off either from glass or $\mathrm{MoSe}_{2} /$ Mo interface.

3.4. Characterization of Isothermally Selenized Mo Films Covered with $\mathrm{Cu}$ and In Layers. The influence of In and Cu coverage on molybdenum to the selenization process of Mo was investigated. The structural evolution of layers is illustrated in Figure 7. In the case of In coverage (see left side photos in Figure 7) at $300^{\circ} \mathrm{C}, \mathrm{Mo}$ is covered with a polycrystalline core of formed In-Se compounds. At higher temperatures, little crystals of In-Se are sparsely standing in the layer giving a possibility to Se molecules to penetrate the layer easily. $\mathrm{Cu}$ on Mo (see right side photos in Figure 7) forms a compact continuous layer with big sintered crystals at lower temperatures. At higher temperatures the crystals in the layer grow larger and at the highest temperatures, gather into large single aggregates. It is visible that the $\mathrm{Cu}$ and In layers on Mo impede the growth of $\mathrm{MoSe}_{2}$ compared with uncovered Mo samples (see Figure 10), while the samples with indium gave thicker $\mathrm{MoSe}_{2}$ layers than the samples with copper. The former is understandable when considering that CuSe forms on Mo a compact continuous coverage seen in Figure 7 that inhibits the access of Se molecules to Mo.

SEM micrographs of Mo samples covered with $\mathrm{Cu}$ and In and selenized at $530^{\circ} \mathrm{C}$ are presented in Figure 8. The formed $\mathrm{MoSe}_{2}$ interlayer is clearly seen on the SEM images (Figures 7 and 8 ) and its existence was confirmed by the EDS line scanning profiles (Figure 9), and results of XRD (Figure 11) and Raman analysis (Figure 12). The XRD analyses confirm that in addition to the hexagonal $\mathrm{MoSe}_{2}$ (JCDPS card 29-0914) phase, large CuSe crystals (JCDPS card 34-0171, 20-1020) and $\mathrm{In}_{2} \mathrm{Se}_{3}$ as agglomerated rounded crystals on the surface 


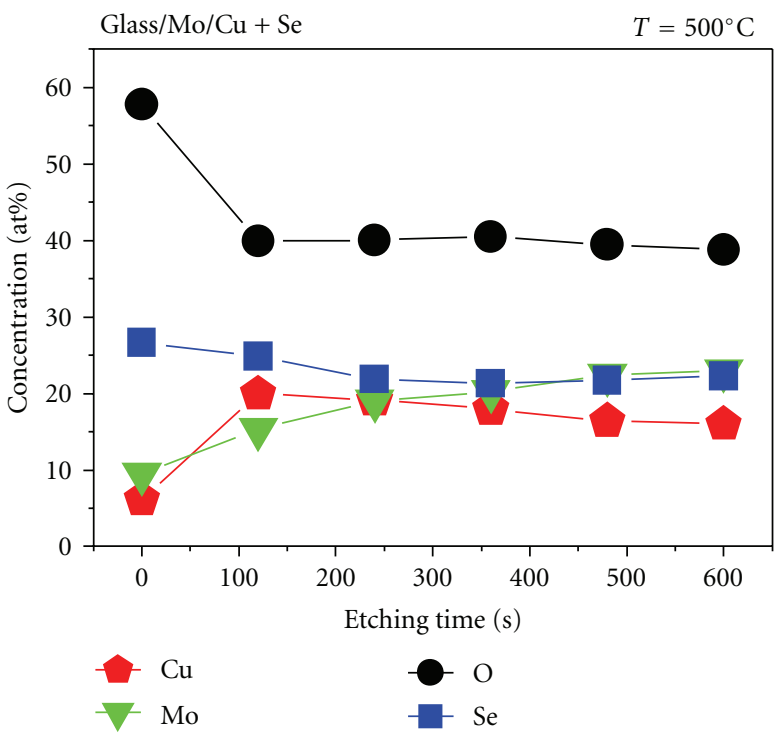

(a)

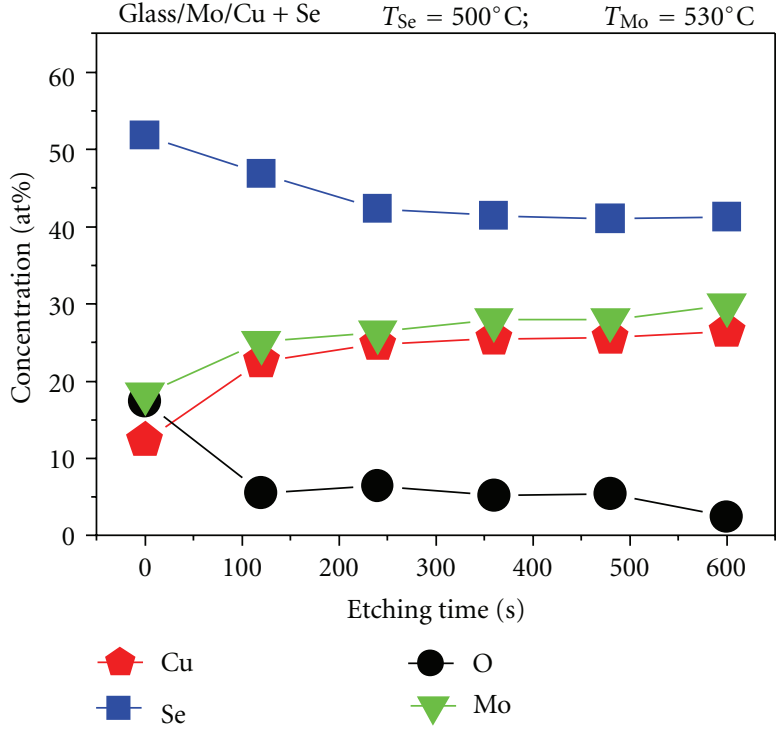

(b)

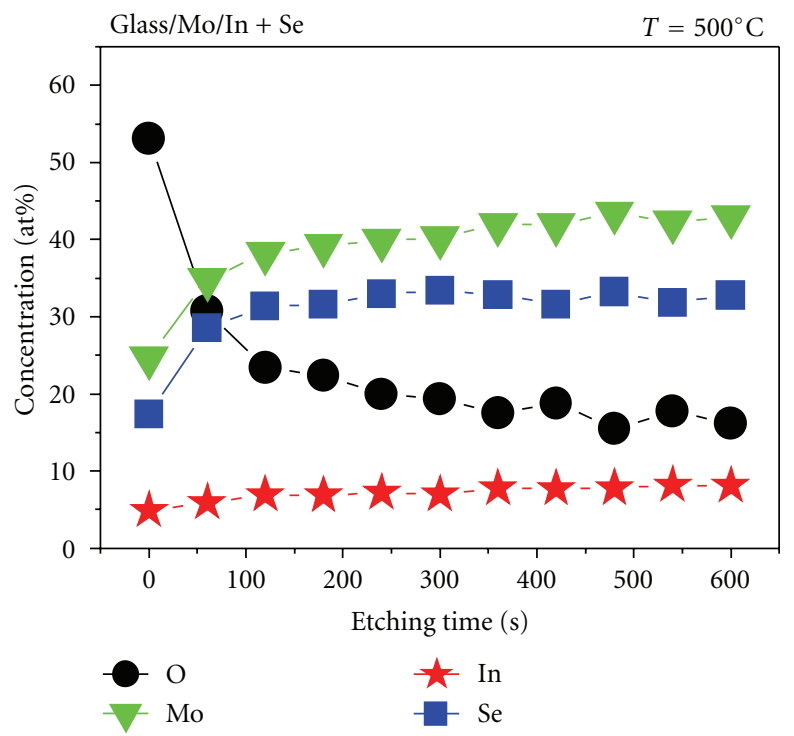

(c)

FIGURE 13: XPS depth profiles of glass/Mo/Cu substrates selenized under (a) isothermal and (b) two-temperature-zone arrangement, (c) XPS depth profile of glass/Mo/In substrates selenized under isothermal arrangement.

(Figures 7 and 8) (JCDPS card 40-1407) are present in selenized $\mathrm{MoSe}_{2}$ films. The formation of CuSe only is understandable if to consider that in closed ampoules the applied Se overpressure avoids the thermal decomposition of $\mathrm{CuSe}$ to $\mathrm{Cu}_{2} \mathrm{Se}$ and $\mathrm{Se}$ that is presumptive by $\mathrm{Cu}$-Se phase diagram [15]. The native logarithmic dependences of the thicknesses of the $\mathrm{MoSe}_{2}$ films as a function of reciprocal temperature are shown in Figure 10. The thickness of $\mathrm{MoSe}_{2}$ on uncovered Mo follows the Arrhenius equation (see Figure 3). It is visible that the $\mathrm{Cu}$ and In layers on Mo impede the growth of $\mathrm{MoSe}_{2}$ in comparison with uncovered Mo samples (see Figure 10), while the influence of indium coverage to the rate of selenization process is less pronounced than the influence of copper coverage.
Micro-Raman spectra in Figures 12(a) and 12(b) of selenized Mo-In and Mo-Cu samples show the peaks at 169, 240, 280, and $350 \mathrm{~cm}^{-1}$ characteristic to $\mathrm{MoSe}_{2}[16,17]$. Analysis of the Raman spectrum (Figure 12(a)) of the glass/ $\mathrm{Mo} / \mathrm{Cu}$ layer selenized at $530^{\circ} \mathrm{C}$ for 30 minutes shows the additional existence of different $\mathrm{Cu}$-Se phases; Raman peaks at 147 and $260 \mathrm{~cm}^{-1}$ belong to CuSe $[18,19]$ and a peak at $270 \mathrm{~cm}^{-1}$ can be associated with $\mathrm{Cu}_{2} \mathrm{Se}$ or $\mathrm{CuSe}_{2}$ [20]. Analysis of the Raman spectrum of the glass/Mo/In layer selenized at $530^{\circ} \mathrm{C}$ for 30 minutes (Figure $12(\mathrm{~b})$ ) reveals beside $\mathrm{MoSe}_{2}$ the existence of In containing phase $\mathrm{In}_{2} \mathrm{Se}_{3}$ Raman peaks at 91, 148, 182, 204, and $256 \mathrm{~cm}^{-1}[21,22]$.

The XPS depth profiles of selenized glass/Mo/In and glass/Mo/Cu layers are presented in Figure 13. It is seen that 
all the Mo-Se layers contain oxygen and that some $\mathrm{Cu}$ and In from surface have diffused into Mo-Se layer. It is known from the literature that the as deposited Mo films, if sputtered onto unheated substrates, contain significant amount of oxygen bound as $\mathrm{MoO}_{2}$ and $\mathrm{MoO}_{3}[8,9]$. In [10] the oxygen content of rf sputtered Mo films was 8 at $\%$ as determined by RBS. It is important to point out that in the case of two-temperature zone arrangement the concentration of oxygen in the layers is diminished in comparison with the isothermal selenization. This can be explained by $\mathrm{SeO}_{2}$ formation that has remarkable vapor pressure at the applied temperatures and the twotemperature arrangement which enables $\mathrm{SeO}_{2}$ to condensate into the lower temperature zone (melting point of solid $\mathrm{SeO}_{2}$ is $\left.340-350^{\circ} \mathrm{C}[23]\right)$.

\section{Conclusions}

The formation of $\mathrm{MoSe}_{2}$ of $p$-type conductivity on Mo substrates at temperatures from 375 to $580^{\circ} \mathrm{C}$ dependent on selenium vapor pressure and annealing duration was studied. We found that the thickness of $\mathrm{MoSe}_{2}$ layer on Mo-foil depends on the selenization duration linearly and on the Se vapor pressure as a function $d_{L} \sim P_{\mathrm{Se}}^{1 / 2}$. According to XPS analysis, $\mathrm{Cu}$ and In have been diffused into Mo-Se layer. It is an important finding that the residual oxygen content in the formed $\mathrm{MoSe}_{2}$ layers was much lower in the case of twotemperature zone arrangement. In the case of isothermal arrangement, quick formation of a relatively high vapor pressure of Se in the vicinity of the Mo sample (determined by the heat treatment temperature) allows a faster start of the $\mathrm{MoSe}_{2}$ formation in comparison with two-temperature zone arrangement. We can conclude that the selenization process in isothermal arrangement can be controlled by the annealing duration and temperature if the added amount of elemental Se is unlimited or by the limited amount of Se. The thickness of $\mathrm{MoSe}_{2}$ on glass/Mo samples follows the Arrhenius equation; the thickness (in native logarithmic scale) of the formed $\mathrm{MoSe}_{2}$ layer increases linearly with the reciprocal selenization temperature. From the Arrhenius plot, the activation energy of the process was determined as $E_{a}=0.7 \pm$ $0.1 \mathrm{eV}$. The optimum selenization temperature was $530^{\circ} \mathrm{C}$ which resulted in uniform $\mathrm{MoSe}_{2}$ layers without cracks and with the $c$-axis orientation parallel to Mo surface. At higher temperatures, the tension between the layers was found to be remarkable and resulted in cracks and bad adhesion, peeling off $\mathrm{MoSe}_{2}$ either from glass or from $\mathrm{MoSe}_{2} / \mathrm{Mo}$ interface. $\mathrm{Cu}$ and In layers on Mo impede the growth of $\mathrm{MoSe}_{2}$ compared with uncovered Mo samples. Due to the smaller crystal size of formed $\mathrm{In}_{2} \mathrm{Se}_{3}$ compared to compact continuous coverage of CuSe, the penetration of Se molecules is faster through $\mathrm{In}_{2} \mathrm{Se}_{3}$ crystals, and the thickness of $\mathrm{MoSe}_{2}$ layer is thicker on the glass/Mo/In samples than on glass/Mo/Cu samples under the same selenization conditions.

\section{Acknowledgments}

Financial support of the Estonian Ministry of Science and Higher Education under by Contract T099 and of Estonian
Science Foundation under Contract nos. 6160, 6179, 8147, and 8964 is gratefully acknowledged.

\section{References}

[1] D. Abou-Ras, G. Kostorz, D. Bremaud et al., "Formation and characterisation of $\mathrm{MoSe}_{2}$ for $\mathrm{Cu}(\mathrm{In}, \mathrm{Ga}) \mathrm{Se}_{2}$ based solar cells," Thin Solid Films, vol. 480-481, pp. 433-438, 2005.

[2] P. A. Berseth, T. A. Hughes, R. Schneidmiller, A. Smalley, and D. C. Johnson, "Low temperature synthesis using modulated elemental reactants: a new metastable ternary compound, $\mathrm{NixMoSe}_{2}$," Solid State Sciences, vol. 4, no. 5, pp. 717-722, 2002.

[3] H. Tributsch, "Hole reactions from d-energy bands of layer type group VI transition metal dichalcogenides: new perspectives for electrochemical solar energy conversion," Journal of the Electrochemical Society, vol. 125, no. 7, pp. 1086-1093, 1978.

[4] W. Sienicki, "Semiconductor properties of molybdenum diselenide intercalated with atoms of the III-A group elements," Materials Chemistry and Physics, vol. 68, no. 1-3, pp. 119-123, 2001.

[5] J. C. Bernède, J. Pouzet, and Z. K. Alaoui, "Preparation and characterization of molybdenum diselenide thin films," $A p$ plied Physics A Solids and Surfaces, vol. 51, no. 2, pp. 155-159, 1990.

[6] R. Krishnan, E. A. Payzant, R. Kacnyzki et al., "Reaction kinetics and pathways of $\mathrm{MoSe}_{2}$," in Proceedings of the 35th IEEE Photovoltaic Specialists Conference (PVSC '10), pp. 1006-1008, June 2010.

[7] Y. I. Gerasimov, A. N. Krestovnikov, and S. I. Gorbov, Chimicheskaya Thermodynamica $v$ Cvetnoi Metallurgii, Izdatelstvo Metallurgija, Moscow, Russia, 1974.

[8] N. Barreau and J. C. Bernède, "Low-temperature preparation of $\mathrm{MoS}_{2}$ thin films on glass substrate with NaF additive," Thin Solid Films, vol. 403-404, pp. 505-509, 2002.

[9] H. A. Al-Thani, F. S. Hasoon, M. Young et al., "The effect of Mo back contact on Na out-diffusion and device performance of $\mathrm{Mo} / \mathrm{Cu}(\mathrm{In}, \mathrm{Ga}) \mathrm{Se}_{2} / \mathrm{CdS} / \mathrm{ZnO}$ solar cells," in Proceedings of the 29th IEEE Photovoltaic Specialists Conference (PVSC '02), pp. 720-723, May 2002.

[10] M. Bodegård, K. Granath, L. Stolt, and A. Rockett, "Behaviour of Na implanted into Mo thin films during annealing," Solar Energy Materials and Solar Cells, vol. 58, no. 2, pp. 199-208, 1999.

[11] J. Songster and A. D. Pelton, "The Na-Se (sodium-selenium) system," Journal of Phase Equilibria, vol. 18, no. 2, pp. 185-189, 1997.

[12] D. Braunger, D. Hariskos, G. Bilger, U. Rau, and H. W. Schock, "Influence of sodium on the growth of polycrystalline $\mathrm{Cu}(\mathrm{In}, \mathrm{Ga}) \mathrm{Se}_{2}$ thin films," Thin Solid Films, vol. 361, pp. 161$166,2000$.

[13] A. Jäger-Waldau, M. Lux-Steiner, R. Jäger-Waldau, R. Burkhardt, and E. Bucher, "Composition and morphology of $\mathrm{MoSe}_{2}$ thin films," Thin Solid Films, vol. 189, no. 2, pp. 339$345,1990$.

[14] L. Kaupmees, M. Altosaar, O. Volobujeva, and P. Barvinschi, "Study of Mo selenisation process on different Mo substrates," in Thin-Film Compound Semiconductor Photovoltaics-MRS spring meeting, A. Yamada, C. Heske, M. Contreras, M. Igalson, and S. J. C. Irvine, Eds., vol. 1165, Materials 
Research Society Proceedings, San Francisco, Calif, USA, April 2009.

[15] V. M. Glazov, A. S. Pashinkin, and V. A. Fedorov, "Phase equilibria in the Cu-Se system," Inorganic Materials, vol. 36, no. 7, pp. 641-652, 2000.

[16] W. Witte, R. Kniese, A. Eicke, and M. Powalla, "Influence of the $\mathrm{Ga}$ content on the $\mathrm{Mo} / \mathrm{Cu}(\mathrm{In}, \mathrm{Ga}) \mathrm{Se}_{2}$ interface formation," in Proceedings of the of the 4th IEEE World Conference on Photovoltaic Energy Conversion (WCPEC '06), p. 553, Waikoloa, Hawaii, USA, May 2006.

[17] V. Y. Fominski, R. I. Romanov, A. V. Gusarov, and J. P. Celis, "Pulsed laser deposition of antifriction thin-film $\mathrm{MoSe}_{x}$ coatings at the different vacuum conditions," Surface and Coatings Technology, vol. 201, no. 18, pp. 7813-7821, 2007.

[18] G. Morell, R. S. Katiyar, S. Z. Weisz, T. Walter, H. W. Schock, and I. Balberg, "Crystalline phases at the p- to n-type transition in Cu-ternary semiconducting films," Applied Physics Letters, vol. 69, no. 7, pp. 987-989, 1996.

[19] G. B. Sakr, I. S. Yahia, M. Fadel, S. S. Fouad, and N. Romević, "Optical spectroscopy, optical conductivity, dielectric properties and new methods for determining the gap states of CuSe thin films," Journal of Alloys and Compounds, vol. 507, no. 2, pp. 557-562, 2010.

[20] E. Anastassakis, "Light scattering in transition metal diselenides $\mathrm{CoSe}_{2}$ and $\mathrm{CuSe}_{2}$," Solid State Communications, vol. 13, no. 9, pp. 1297-1301, 1973.

[21] J. Weszka, P. Daniel, A. Burian, A. M. Burian, and A. T. Nguyen, "Raman scattering in $\mathrm{In}_{2} \mathrm{Se}_{3}$ and $\mathrm{InSe}_{2}$ amorphous films," Journal of Non-Crystalline Solids, vol. 265, no. 1, pp. 98104, 2000.

[22] R. Lewandowska, R. Bacewicz, J. Filipowicz, and W. Paszkowicz, "Raman scattering in $\alpha$ - $\mathrm{In}_{2} \mathrm{Se}_{3}$ crystals," Materials Research Bulletin, vol. 36, no. 15, pp. 2577-2583, 2001.

[23] Spravotchnik Chimica II, Moscow, Russia, Chimia, 1964. 

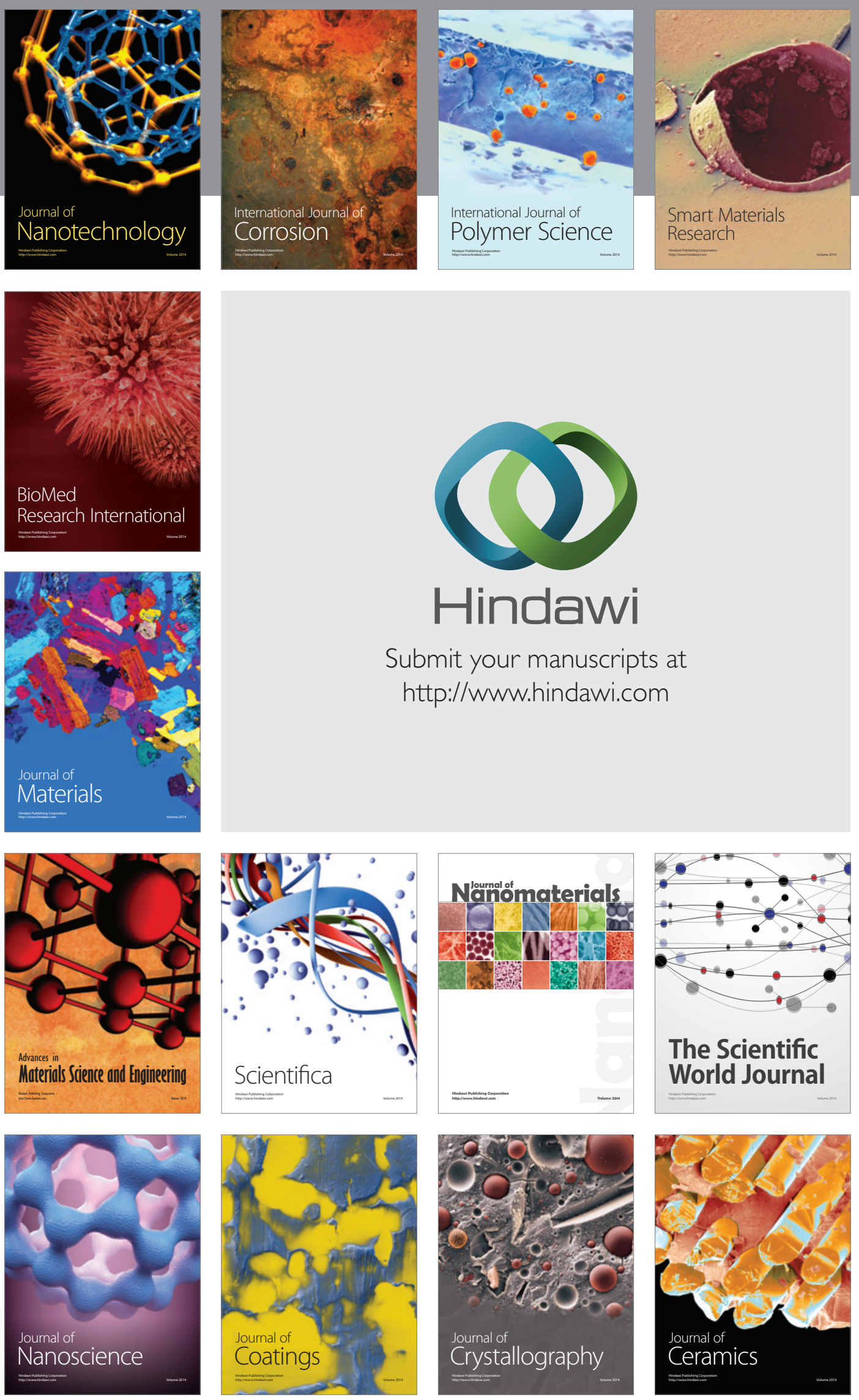

The Scientific World Journal

Submit your manuscripts at

http://www.hindawi.com

\section{World Journal}

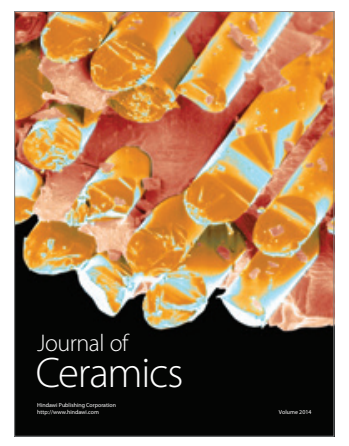

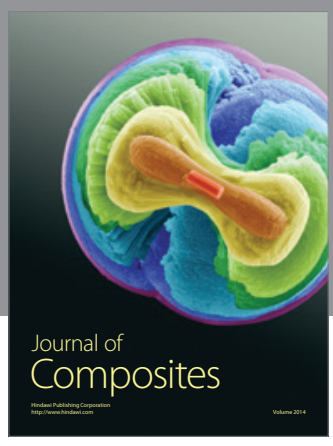
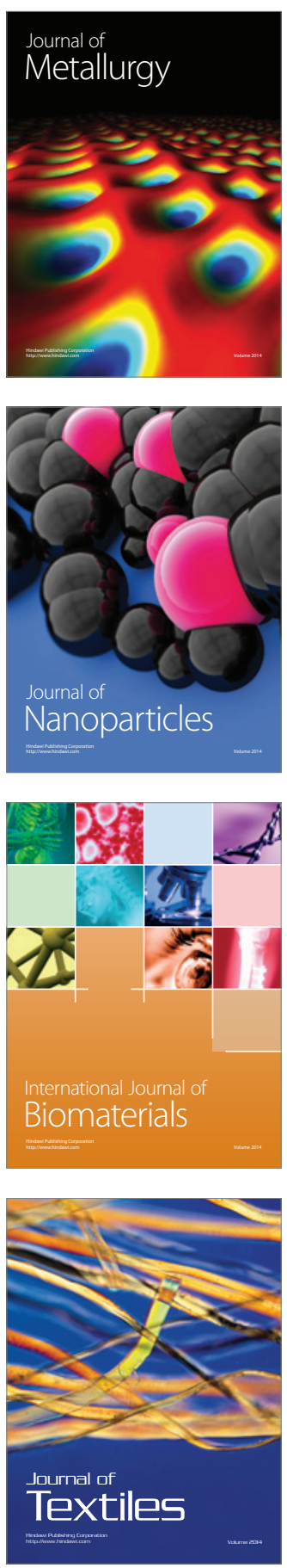